\title{
BUDAYA KESURUPAN SENI TRADISI JARANAN DI BANYUWANGI
}

\author{
Rizky Agung ${ }^{1}$, Dhalia Soetopo ${ }^{2}$ \\ Fakultas Keguruan dan Ilmu Pendidikan, Universitas PGRI Banyuwangi ${ }^{1}$ \\ Email: rizkyagung200195@gmail.com \\ Email:dhalia.soetopo@gmail.com
}

\begin{abstract}
Tari Jaranan Banyuwangi adalah kesenian tari tradisional yang kaya akan nilai seni dan budaya, tarian ini juga sangat kental akan kesan magis dan nilai spiritual. Tari Jaranan ini merupakan kesenian yang sangat terkenal di banyuwangi yang tersebar di beberapa kecamatan, seperti Kecamatan Banyuwangi, Kabat, Rogojampi, Kalipuro, Licin, Singonjuruh, Rogojampi, Giri dan kecamatan Glagah. Penelitian terdahulu tentang Jaranan sudah banyak dilakukan. Dari beberapa penelitian terdahulu tentang Jaranan, penelitian ini sangat berbeda dari penelitian terdahulu yang fokus penelitiannya pada sejarah awal seni jaranan, nilai-nilai/ makna seni jaranan, perkembangan seni jaranan, dan bentuk pertunjukan seni jaranan. Penelitian ini lebih terfokus pada budaya "Kesurupan" yang meliputi proses ritual kesurupan, makna kesurupan dan perubahan budaya kesurupan dalam ritual tradisi jaranan Banyuwangi. Peneliti menggambildata di tiga Kecamatan yaitu Kecamatan Banyuwangi yaitu Grup Jaranan Baluk, kecamatan Glagah yaitu Grup Jaranan KarangAsem dan Kecamatan Giri yaitu Grup Jaranan Tresno Budoyo. Peneliti menggunakan Metode deskriptif kualitatif dengan teknik pengumpulan data yaitu observasi, wawancara dan dokumentasi.
\end{abstract}

Kata kunci : Budaya, Kesenian, Tradisi, Kesurupan, Jaranan, Banyuwangi

\begin{abstract}
ABSTRAK
Banyuwangi Jaranan Dance is a traditional art that is rich in artistic and cultural values, this dance is also very thick to the impression of magical and spiritual value. Jaranan dance is a very famous art in banyuwangi spread in several districts, such as District Banyuwangi, Kabat, Rogojampi, Kalipuro, Licin, Singonjuruh, Rogojampi, Giri and Glagah district. The usual research on Jaranan has been done a lot. From several studies on jaranan, this study is very different from the initial research that focuses on the initial research of jaranan art, the values / meaning of jaranan art, the art of jaranan performance, and the art of jaranan performance. This research is more focused on the culture of "Kesurupan" which includes the process of ritual possession, the meaning of possession and culture in ritual jaranan Banyuwangi. Researchers took data in three sub-districts of Banyuwangi, namely Jaranan Baluk Group, Glagah sub-district, Jaranan Karang Asem Group and Giri Sub-District, Tresno Budoyo Jaranan Group. Researchers use qualitative descriptive method with data recognition techniques, interviews and documentation.
\end{abstract}

Keywords: Culture, Art, Tradition, Trance, Jaranan, Banyuwangi 


\section{Pendahuluan}

Banyuwangi adalah kabupaten yang berada di ujung timur propinsi Jawa Timur yang memiliki potensi kepariwisataan cukup melimpah. Keberagaman itu dapat dilihat berdasarkan kultur masyarakatnya secara dominan terbagi ke dalam tiga etnik yaitu etnik Jawa Mataraman, etnik Madura Pandalungan, dan etnik Using. Keaneragaman etnik masyarakat tersebut melahirkan kekayaan budaya yang menjadi identitas diri yang tidak terhitung nilainya .

Menurut Koentjaraningrat dalam Veramita Sari (2017:2)di lingkungan pedesaan, keanekaragaman warna masyarakat dan juga kebudayaan Indonesia masih tetap terjaga, sehingga perbedan kebudayaan-kebudayaan yang ada dari beragam suku bangsa hingga sekarang masih terlihat mencolok. Kebudayaan tersebut merupakan hasil karya cipta dari pemikiran, perasaan dan nurani manusia. Hasil dari ini semua, akan membentuk kebudayaan yang membuat setiap kelompok-kelompok manusia memiliki ciri-ciri yang berbeda. Kebudayaan tersebut biasanya digunakan sebagai sarana komunikasi dalam kehidupan mereka, baik komunikasi antara invididu maupun komunikasi antara manusia dengan alam sekitarnya.

Menurut Koentjaraningrat

$(1999: 72)$

kebudayaan adalah seluruh sistem gagasan dan rasa, tindakan, serta karya yang dihasilkan manusia dalam kehidupan bermasyarakat, yang dijadikan miliknya dengan belajar. Salah satu bentuk kebudayaan adalah kesenian yang merupakan wujud dari suatu kemampuan anggota masyarakat. Kesenian sebagai subsistem kebudayaan sangatlah penting bagi suatu kehidupan umat manusia, oleh sebab itu dalam kehidupan manusia tidak mungkin terlepas dari peranan seni. Kesenian merupakan sarana yang digunakan untuk mengekspresikan rasa dari keindahan manusia. Segala bidang terdapat unsur-unsur seni, baik bidang perdagangan, pendidikan, serta keagamaan pun tidak dapat terpisahkan dari unsur kesenian. Terlihat dari segala aktifitas yang dilakukan manusia tidak lepas dari seni itu sendiri. Seni merupakan kebutuhan dasar dari manusia dimanapun mereka berada, dalam berbagai situasi serta dalam segala kondisi sehingga wujud seni yang diciptakan oleh manusia pun beragam dan banyak jenisnya. 
Kebudayaan masyarakat mencakup berbagai macam aspek dalam kehidupan. Salah satu kebudayaan yang dimiliki oleh masyarakat Indonesia adalah kesenian tradisional. Setiap daerah tentunya memiliki ciri khas kesenian tradisional yang berbeda satu dengan yang lainnya. Kesenian tradisional itu dapat mencakup seni tari, seni rupa, seni musik, dan lainnya.

Kesenian merupakan salah satu dari ketujuh unsur kebudayaan yang mempunyai wujud, fungsi, dan arti dalam kehidupan masyarakat. Bentuk-bentuk kesenian yang tersebar di seluruh tanah air menunjukkan corak-corak dan karakter yang beraneka ragam. Corak atau karakter tersebut muncul karena banyak dipengaruhi oleh sifat atau karakter budaya setempat, darimana masyarakat berasal atau bertempat tinggal. Kesenian berperan sebagai media komunikasi, sehingga suatu bentuk kesenian yang akan lahir, tumbuh dan berkembang berdasar situasi maupun kondisi masyarakat di mana kesenian tersebut menampakkan eksistensinya. Sepanjang sejarah kehidupan manusia, seni selalu hadir sebagai unsur kebudayaan yang penting. Hal ini disebabkan seni memiliki daya ekspresi sehingga mampu merefleksikan secara simbolik komunikasi untuk berekspresi, menyampaikan pesan, kesan dan tanggapan manusia terhadap stimulasi dari lingkungan (Setyorini, 2013:1\&2).

Kesenian di Indonesia mempunyai beragam bentuk, salah satunya seni pertunjukan. Dalam seni pertunjukan terdapat beberapa cabang seni, diantaranya adalah : seni musik, seni tari, seni rupa, seni drama, dan seni sastra. Salah satu cabang kesenian yang akan dibahas adalah seni tari. Menurut Soedarsono dalam Kartika Nugraheni (2015:2)tari adalah suatu alat ekspresi dan komunikasi berupa bahasa gerak yang secara universal dapat dilakukan dan dinikmati oleh siapa saja, kapan saja, dan dimana saja. Salah satu seni tari yang kini masih dipertahankan dan dilestarikan oleh masyarakat Banyuwangi adalah kesenian Tari Jaranan Banyuwangi.

Menurut Wijayanti(2016:1) Seni Tari Jaranan adalah seni tradisional yang kaya akan nilai seni dan budaya, tarian ini sangat kental akan kesan magis dan nilai spiritual.Seni pertunjukan jaranan yang identik dengan terjadi kesurupan dan atraksi-atraksi yang dilakukan oleh para penari-penari jaranan, membuat seni pertunjukan jaranan memiliki daya tarik tersendiri. Pada saat penari kemasukan roh 
halus maka tugas dari pawang adalah menyadarkannya kembali. Sebelum pemain sadar biasanya roh halus yang masuk kedalam tubuh penari jaranan meminta halhal yang tidak wajar, seperti meminta bunga, memakan pecahan kaca, meminta kelapa dan pernah juga ada kejadian penari yang kesurupan ada yang melarikan diri. Keadaan kerasukan ini menarik, karena peristiwa tersebutmerupakan bukti yang paling jelas dari adanya hubungan yang erat antara seni pertunjukan jaranan dengan kepercayaan disuatu masyarakat. Masyarakat masih percaya akan adanya roh halus yang ada pada suatu tempat yang dianggap sakral.

Seni Tari Jaranan Banyuwangi tersebar di beberapa kecamatan, seperti Kecamatan Banyuwangi, Kabat, Rogojampi, Kalipuro, Licin, Singonjuruh, Rogojampi, Giri dan kecamatan Glagah. Penulis mengambil tempat penelitian di tiga kecamatan, yaitu Kecamatan Banyuwangi, Giri dan Glagah, alasannya yang pertama karena mayoritas masyarakat di tiga kecamatan ini adalah masyarakat etnik Using yang menjadikan kesenian jaranan sebagai hiburan wajib dalam acara sunatan dan pernikahan. Alasan kedua yaitu karena ketiga wilayah ini mempunyai grup jaranan yang namanya tersohor di penjuru wilayah Banyuwangi diantaranya yaitu jarananan Joyo Kusumo, Jaranan Karang Asem dan Jaranan Baluk serta alasan yang ketiga yaitu mengenai lokasi yang mudah dijangkau peneliti dalam melakukan penelitian agar penelitian ini dapat berjalan maksimal.

Dari beberapa penelitian terdahulu tentang Jaranan, penelitian ini sangat berbeda dari penelitian terdahulu yang fokus penelitiannya pada sejarah awal seni jaranan, nilai-nilai/ makna seni jaranan, perkembangan seni jaranan, dan bentuk pertunjukan seni jaranan. Penelitian ini lebih terfokus pada budaya "Kesurupan" yang meliputi proses ritual kesurupan, makna kesurupan dan perubahan budaya kesurupan dalam ritual tradisi jaranan Banyuwangi. Berangkat dari uraian di atas, maka penulis ingin melakukan penelitian yang berjudul,

\section{Budaya "Kesurupan" Seni Tradisi Jaranan Banyuwangi".}

\section{Kajian Literatur dan Pengembangan Hipotesis}

\section{a. Kebudayaan}

Indonesia kaya akan budaya, istiadat dan tradisi, maupun seni yang dimiliki merupakan karya budaya pendahulu kita. Menurut Koentjaraningrat dalam Sulistyanto (2012:1), bahwa kebudayaan itu mempunyai tiga wujud yaitu: yang pertama sebagai 
suatu kompleks dari ide-ide, gagasan, nilainilai, norma-norma, peraturuan. Yang kedua, kebudayaan sebagai suatu kompleks aktivitet kelakuan berpola dari manusia dalam masyarakat. Dan yang ketiga, wujud kebudayaan sebagai benda-benda hasil karya manusia. Kebanyakan orang hanya mengenal sebatas hiburan tanpa mengetahui makna sebenarnya tentang budaya.

Menurut Suparlan dalam Made Karthadinata(2006:12) kebudayaan adalah sesuatu yang bersifat abstrak, yaitu pedoman menyeluruh yang berisi sistem-sistem pengetahuan, sistem-sistem kepercayaan, sistem-sistem gagasan dan sistem-sistem nilai bagi segala tindakan manusia dalam memenuhi kebutuhan hidupnya. Kebudayaan ada, berkembang, dan dibakukan dalam tradisi-tradisi sosial suatu masyarakat. Kebudayaan adalah milik masyarakat yang dipergunakan secara bersama, sebagai pedoman atau kerangka acuan warga masyarakat yang bersangkutan dalam berbagai tingkah laku yang bertalian dengan upaya untuk memenuhi kebutuhan hidupnya. Kendati dalam kenyataan empirik pada tingkat individu dimungkinkan terjadi penyimpangan tingkah laku sebagai akibat pengetahuan kebudayaan yang dimiliki.
Menurut Liliwei (2003:8) "kebudayaan adalah komunikasi simbolis, simbolisme itu adalah ketrampilan kelompok, pengetahuan, sikap, nilai dan motif. Jadi, kebudayaan masyarakat berupa kesenian merupakan media untuk berkomunikasi dengan masyarakat luas bahkan kepada sang Maha Pencipta”.

JarananBanyuwangi sebagai hasil karya seni merupakan sistem komunikasi dari bentuk dan isi. Bentuk yang berupa realitas gerak, musik, busana, property, dan peralatan secara visual tampak oleh mata. Namun, isi yang berupa tujuan, harapan, dan cita-cita adalah komunikasi maya yang hanya dapat dipahami oleh masyarakat landasan konseptual yang bersumber pada kompleksitas sistem simbol. Secara jelas Umar Kayam (1981:48) mengatakan "Sudah waktunya kreativitas kesenian dipahami dalam konteks perkembangan masyarakat", jadisebuah seni budaya di Indonesia itu pada umumnya bertujuan memajukan sekaligus sebagai harta warisan dari nenek moyang.

Setiap orang, dalam arti tertentu, membutuhkan sarana atau media untuk berkomunikasi. Media ini terutama ada dalam bentuk-bentuk simbolis sebagai pembawa maupun pelaksana makna atau pesan yang akan dikomunikasikan. Beberapa etnik masyarakat seperti etnik Jawa dan Using, melakukan budaya ritual 
adat untuk berkomunikasi dengan leluhurnya sebagai bentuk penghormatan dan rasa syukur.

\section{b. Kese nian Tari Jaranan Banyuwangi}

Seni berasal dari bahasa Melayu yang berarti kecil. Seni adalah keindahan dan seni adalah tujuan yang positif menjadikan penikmat merasa dalam kebahagiaan. Seni adalah bentuk yang pengungkapannya dan penampilannya tidak pernah menyimpang dari kenyataan dan seni itu adalah meniru alam. Seni adalah sebuah impian karena rumus-rumus tidak dapat mengihtiarkan kenyataan

Karya seni merupakan sebuah benda atau artefak yang dapat dilihat, didengar, atau dilihat dan sekaligus didengar (visual, audio, dan audio-visual), seperti lukisan, music dan teater (Sumardjo, 2000:45).

Seni tari merupakan seni yang dinikmati melalui media penglihatan dan pendengaran (audio-visual). Tari merupakan sebuah seni kolektif, sebab dalam proses dan kerangka wujudnya tempat dibentuk oleh berbagai disiplin seni yang lainmisalnya sastra, musik, seni rupa, dan seni drama (Hidajat, 2005:1).

Tari sebagai karya seni merupakan alat ekspresi dan sarana komunikasi seorang seniman kepada orang lain (penonton atau penikmat). Sebagai alat ekspresi, tari mampu menciptakan untaian gerak yang dapat membuat penikmatnya peka terhadap sesuatu yang ada dan terjadi. Tari adalah sebuah ungkapan, pernyataan, dan ekspresi penciptanya yang memuat komentarkomentar mengenai realitas, yang bisa merasuk di benak penikmatnya setelah pertunjukan selesai (Jazuli, 2007:4)

Kesenian jaranan merupakan wujud dari bentuk rasa syukur terhadap kekuatan animisme dan dinamisme, diwujudkan dalam bentuk tarian maupun doa atau kesenian religius lainnya. Ditinjau dari arti kata Jaranan berasal dari kata jaran atau kuda mendapat akhiran-an menunjukan bentuk tidak asli atau dalam kata lain tiruan (replika). Dalam budaya Jawa jaran merupakan simbol kekuatan, lambang keperkasaan dan lambang kesetiaan. Ketika manusia menggunakan kuda sebagai kendaraan atau wahana, maka manusia digambarkan sedang berjuang mengarungi hidup menuju tujuan hidupnya atau yang dikenal dengan cita-cita. (Trisakti, 2013:379).

Group Jaranan Banyuwangi menyebar di hampir seluruh kabupaten Banyuwangi. Sebutan Group Jaranan 
biasanya disesuaikan dari asal Desa Jaranan tersebut berasal, Seperti, Jaranan Mangir berasal dari Desa Mangir, Jaranan Karangasem berasal dari Desa Karangasem, Jaranan Baluk dari Desa Baluk, dan Jaranan Licin berasal dari Desa Licin. Kesenian jaranan Banyuwangi masih tetap hidup karena banyak masyarakat Banyuwangi yang menjadikan pertunjukan seni tradisi jaranan Banyuwangi sebagai acara hiburan wajib dalam acara sunatan dan pernikahan. Pada perkembangannya di era modern saat ini pertunjukan kesenian Jaranan sudah sedikit mengalami perubahan dibeberapa sisi. Sebuah kondisi yang tampak ketika sisi magis yakni pada kondisi kesurupan telah diminimalisasi dan mengalami bentuk penyesuaian.

\section{c. Kesurupan}

Menurut Wallace dalam Springate (2009:5) Konsep kesurupan adalah sebuah fenomena tentang mahluk halus yang menguasai pikiran perasaan, dan intelek (kesanggupan untuk membuat keputusan) pada diri seseorang dengan menyatu pada kesadarannya.

Kesurupan adalah kemasukan setan atau roh, orang yang kemasukan roh maka tidak sadar lagi. Hal ini mengalami keadaan di luar kesadaran manusia kemudian tidak ingat apa-apa, seperti halnya penari jaranan yang mengalami kesurupan atau kesurupan akan melakukan gerakan di luar kesadarannya, karena telah dikuasai oleh roh yang masuk ke dalam tubuh penari melalui pawang. Dalam kepercayaan masyarakat Jawa, kesurupan merupakan sesuatu yang dilandasi dengan adanya masuknya roh dalam diri seseorang disamping itu juga diperlukan sesaji yang merupakan suatu cara untuk memanggil roh untuk datang melalui barang atau benda. Hal ini mengingat seni pertunjukan jaranan tidak lepas dari gerakan yang atraktif atau akrobatik yang dianggap penuh dengan unsur kekuatan gaib serta sulit diterima dengan akal sehat(Wijayanti, 2016:19).

Budaya kesurupan yang terdapat dalam Seni Tradisi Jaranan Banyuwangi diawali dengan ritual pemanggilan roh halus dengan media sarana dan prasarana yang menunjang seperti sesajen diantarnya yaitu kembang tujuh rupa, beras ketan kuning, lauk ikan, ayam hitam, batok kelapa yang dibakar serta kemenyan. Dalam proses kesurupan lakon akan melakukan atraksi dengan dengan salah satu media yaitu Barong/ macan-macanan lalu diiringi dengan irama tabuhan musik yang sangat 
kencang. Pada saat lakon kerasukan mahluk halus, roh halus tersebut yang menguasai pikiran, perasaan, dan intelek (kesanggupan untuk membuat keputusan) pada diri seseorang dengan menyatu pada kesadarannya. Alhasil mahluk halus ini bisa menguasai tindakan seseorang, menguasai jiwanya dan tingkah laku. Oleh karena itu, tingkah laku seseorang yang kesurupan di luar nalar manusia, mereka menari seperti hewan, berlariankan ke arah penonton yang menggodanya dan melakukan atraksi seperti memakan bunga, beling, batok kelapa,serta ayam hidup.

\section{Metode Penelitian}

Metode penelitian menggunakan metode deskriptif kualitatif yaitu dengan cara menguraikan dan menggambarkan aspek yang diteliti. Penelitian kualitatif data yang diperoleh berupa kata-kata melalui informasi dari para pendukung, tulisan, dan foto. Metode deskriptif adalah tehnik pengumpulan data yang berupa kata-kata, gambar, dan bukan angka-angka. Data yang dikumpulkan dapat berupa naskah wawancara, catatan lapangan, foto, vidiotape, dokumentasi pribadi, catatan atau memo, dan dokumentasi resmi lainnya (Moleong, 2011 : 11). Observasi menjadi teknik pengambilan data dilapangan dengan cara melakaukan pengamatan langsung dilapangan (Agus Mursidi, 2016:96)

Data yang diperoleh dengan wawancara mendalam dengan berbagai pihak yang bersangkutan. Setelah itu data yang diperoleh kemudian dapat dikelola dan dianalisis, serta data tersebut dipilah-pilah disesuaikan dengan pembahasan.. Selanjut mendiskripsikan dan disimpulkan. Peneliti juga menggunakan metode Trianggulasi untuk menguji keabsahan data, sehingga dapat memperkuat data, untuk membuat peneliti yakin tentang kebenaran dan kelengkapan data. Penelitian ini bertujuan untuk mendeskripsikan tentang budaya kesurupan seni tradisi jaranan banyuwangi yang berada Kabupaten Banyuwangi Provinsi Jawa Timur.

\section{Daftar Pustaka}

Handoko, Agus Dwi. 2014. "Perkembangan Seni Tari Jaranan Buto Di Kecamatan Cluring Kabupaten Banyuwangi Tahun 1963-2007".e-Journal Pendidikan Sejarah. Volume 2, No 3, Oktober 2014.

Hidayat, Robbi. 2015. "Wawasan Seni Tari. Pengetahuan Praktis Bagi Guru Seni Tari. Malang”. Skripsi.Jurusan Seni dan Desain Fakultas Sastra Universitas Negeri Malang dengan Unit Pengembangan Profesi Tari. 
Jaya, Indra Ludvi. 2017. "Kesenian Jaranan Sentherewe di Kabupaten Tulungagung Tahun 1958 - 1986".eJournal Pendidikan Sejarah. Volume 5, No. 3, Oktober 2017.

Jazuli, M. 2007. Pendidikan Seni Budaya. Suplemen Pembelajaran Tari. Semarang: UNNES PRESS

Kartikasari, Dewi. 2014. "Bentuk, Makna, Dan Fungsi Pertunjukan Kuda Lumping Turonggo Tri Budoyo Di Desa Kaligono Kecamatan Kaligesing Kabupaten Purworejo".Jurnal Program Studi Pendidikan Bahasa dan Sastra Jawa_Universitas Muhammadiyah Purworejo.Vol. 04 No. 01 Mei 2014

Kartika Nugraheni, Whinda. 2015. "Bentuk

Penyajian Kesenian Tari Jaranan Thik Di Desa Coper, Kecamatan Jetis Kabupaten Ponorogo Jawa Timur".Skripsi.Fakultas Bahasa dan Seni, Universitas Negeri Yogyakarta

Kayam, Umar. 1981. Seni, Tradisi, Masyarakat. Jakarta: Sinar Harapan.

Koentjaraningrat. 1999. Pengantar Antropologi I. Jakarta: Aksara Baru.

Liliweri, Alo. 2003. Makna Budaya dalam Komunikasi antar Budaya. Yogyakarta: LKIS.

Made Karthadinata, Dewa. 2006. "Barong Dan Rangda: Perkembangan, Proses Pembuatan, Dan Sakralisasi, Serta Pesan-Pesan Budaya Dalam Penampilannya Sebagai Kesenian Tradisional Bali”. Tesis.Universitas Negeri Semarang

Moleong, Lexy J. 2007. Metode Penelitian Kualitatif (Edisi Revisi). Bandung: PT Remaja Rosdakarya

Moleong, Lexy J. 2011. Metode Penelitian Kualitatif. Bandung: PT Remaja Rosdakarya.
Mursidi, Agus, 2016. Dominasi Kiai Dalam Pendidikan di pondok Pesantren Ihya'ulumiddin. Historia Volume 4, nomor 2. UMM Metro

Radhia, Hanifati Alifa. 2016. "Dinamika Seni Pertunjukan Jaran Kepang Di Kota Malang".Jurnal Kajian Seni. Volume 02 No.02 April 2016.

Rahardi, D.S., Sumarno, Sumarjono. 2015. "Perkembangan Kesenian Tradisional Jaran Kencak (Kuda Kencak) Di Kecamatan Yosowilangun Kabupaten Lumajang Tahun 1972-2014”.Artikel Ilmiah Mahasiswa. Universitas Jember.

Springate, Lucy. 2009. "Kuda Lumping dan fenomena Kesurupan Massal: Dua Studi Kasus Tentang Kesurupan Dalam Kebudayaan Jawa”. Skripsi. Universitas muhamadiyah Malang.

Sulistiyanto, Agus. 2012. "Nilai-Nilai Dalam Kesenian Kuda Lumping Turonggo Seto Di Desa Medayu Kecamatan Suruh Kabupaten Semarang Tahun 2012".Skripsi. Sekolah Tinggi Agama Islam Negeri (Stain) Salatiga.

Sugiyono. 2008. Memahami Penelitian Kualitatif $R \& D$. Bandung: Alfabeta.

Sumardjo, Jakob. 2000. Filsafat Seni. Bandung: ITB

Trisakti. 2013. "Bentuk dan Fungsi Seni Pertunjukan Jaranan Dalam Budaya Masyarakat Jawa Timur".Artikel ilmiah. Universitas Negeri Surabaya.

Wijatanti, Hesti. 2016. "Pawang Dalam Seni Pertunjukan Jaranan di Desa Sraten Kecamatan Karanggede Kabupaten Boyolali". Skripsi.Universitas Negri Semarang.

Veramita Sari, Aulia. 2017. "Makna Kesenian Tradisional Kuda Lumping Sebagai Seni 
FKIP UNIVERSITAS PGRI BANYUWANGI SEMINAR NASIONAL

Pendidikan Budaya dan Sejarah "Dibalik Revitalisasi Budaya"

ISBN: 978-602-72362-7-1

Pertunjukan".Skripsi.UniversitasLamp

ung. 